\title{
ANÁLISE DAS VARIAÇÕES SAZONAIS DA TEMPERATURA NA ÁREA URBANA E ENTORNO RURAL DE SANTA MARIA - RS, BRASIL, A PARTIR DE PONTOS FIXOS DE COLETA DE DADOS E IMAGENS ORBITAIS
}

\author{
TRINDADE, Patricia Michele Pereira - patriciatrindade.sr@gmail.com \\ Universidade Federal do Rio Grande do Sul / UFRGS
}

\author{
SALDANHA, Dejanira Luderitz - dejanira.saldanha@ufrgs.br \\ Universidade Federal do Rio Grande do Sul / UFRGS \\ PEREIRA FILHO, Waterloo - waterloopf@gmail.com \\ Universidade Federal de Santa Maria / UFSM
}

\begin{abstract}
RESUMO: O objetivo deste estudo foi verificar as diferenças térmicas entre o espaço urbano e o entorno rural de Santa Maria - RS no período de março/2017 a março/2018 a partir de pontos fixos de coletas de dados e imagens orbitais. A primeira etapa da pesquisa consistiu na distribuição de 10 data loggers em área urbana e rural, registrando a temperatura do ar (Tar) para o período supracitado. A segunda etapa correspondeu à aquisição da temperatura de superfície (TS) a partir imagens termais Landsat 8, compreendendo as quatro estações do ano. O resultado indicou que as áreas urbanas apresentaram Tar superior ao rural principalmente na primavera e verão. O ponto T6, área centro-comercial, apresentou maior aquecimento que os demais durante a noite e madrugada e no ponto T3, maior altitude e densa arborização, verificou-se as menores temperaturas. Os valores de TS também foram superiores em área urbana, no entanto, no meio rural também verificou-se TS elevada em áreas de solo exposto. De modo geral, TS foi superior à Tar, com maior diferença nos pontos urbanos. Destaca-se que a pesquisa possibilitou a análise da variação da temperatura na área de estudo a partir da integração de dados de campo e de sensoriamento remoto.
\end{abstract}

PALAVRAS-CHAVE: Imagens termais, Ilha de calor urbana, Correção de imagens, Experimento de campo.

\section{ANALYSIS OF SEASONAL TEMPERATURE VARIATIONS IN THE URBAN AND SURROUNDING RURAL AREAS OF SANTA MARIA - RS, BRAZIL, FROM FIXED POINTS OF ORBITAL DATA AND IMAGES COLLECTION}

\begin{abstract}
The objective of this study was the assessment of thermal differences between urban space and the surrounding rural area of Santa Maria - RS, Brazil, between the period of March/2017 and March/2018 from fixed points of orbital data and images collection. The first stage of the research consisted in the distribution of 10 data loggers in urban and rural areas, registering the air temperature (AT) for the aforementioned period. The second stage corresponded to the acquisition of surface temperature (ST) from Landsat 8 thermal images, comprising the four seasons of the years. The results indicated that the urban areas presented AT superior to the rural area, especially during spring and summer. The T6 point, a commercial center area, presented higher temperatures than the other areas during the night and before dawn, and in the T3 point, an area with higher altitude and dense forestation, the lowest temperatures were verified. The ST values were also superior in the urban area; however, in the rural environment, high ST was also verified in areas of exposed soil. In general, ST was superior to AT with a higher difference in urban points. It should also be highlighted that the research enabled the analysis of temperature variation in the studied area through the integration of field data and remote sensing.
\end{abstract}

KEYWORDS: Thermal images, Urban heat islands, Image correction, Field experiment. 
ANÁLISIS DE LAS VARIACIONES SAZONALES DE TEMPERATURA EN EL ÁREA URBANA Y ENTORNO RURAL DE SANTA MARIA - RS, BRASIL, A PARTIR DE PUNTOS FIJOS DE COLECTA DE DATOS E IMÁGENES ORBITALES

RESUMEN: El objetivo de este estudio fue verificar las diferencias térmicas entre el espacio urbano y el entorno rural de Santa Maria - RS en el período de marzo/2017 hasta marzo/2018 a partir de puntos fijos de colectas de datos e imágenes orbitales. La primera etapa de la investigación consistió en la distribución de 10 data loggers en áreas urbanas y rurales, registrando la temperatura del aire (Tar) para el período antes mencionado. La segunda etapa correspondió a la adquisición de la temperatura de la superficie (TS) a partir de imágenes termales Landsat 8, que comprenden las cuatro estaciones del año. El resultado indicó que las áreas urbanas presentaron Tar superior al rural principalmente en primavera y verano. El punto T6, área centro-comercial, presentó mayor calentamiento que otros durante la noche y madrugada y en el punto T3, mayor altitud y densa forestación, se verificó las menores temperaturas. Los valores de TS aun fueron superiores en área urbana, sin embargo, en el medio rural también se verificó TS elevada en áreas de suelo expuesto. De modo general, TS fue superior a la Tar, con mayor diferencia en los puntos urbanos. Se destaca que la investigación ha posibilitado el análisis de la variación de la temperatura en el área de estudio a partir de la integración de datos de campo y de detección remota.

PALABRAS CLAVE: Imágenes termales, Isla de calor urbana, Corrección de imágenes, Experimento de campo.

\section{INTRODUÇÃO}

A temperatura mais elevada no meio urbano quando comparada com as áreas rurais pode caracterizar as denominadas "ilhas de calor urbanas" (OKE, 1978; GARTLAND, 2010). O fenômeno pode causar o desconforto térmico na população, comprometendo a saúde, rendimento no trabalho e atividades físicas. Diversos trabalhos foram desenvolvidos com intuito de verificar alternativas para mitigar os efeitos das ilhas de calor como também investigações sobre o conforto térmico (GOBO et al., 2018; BURIOL et al., 2015; STEENEVELD et al., 2014; SANTAMOURIS, 2014; RADHI ET AL., 2013; GAGO ET AL., 2013).

A temperatura do ar (Tar) e temperatura de superfície (TS) são variáveis consideradas para cálculo de índices e análises do conforto térmico. Seguindo esta abordagem, Buriol et al. (2015) quantificaram o conforto térmico em área rural no sul do Brasil, assim como Gobo et al. (2018) que calcularam um modelo empírico de conforto térmico em climas subtropicais. Ambos os trabalhos consideraram dados de estações meteorológicas de coleta de dados, no entanto, cabe destacar que muitas vezes existe a carência desses equipamentos em áreas urbanas.

Aliado a isso, existem os produtos e técnicas de sensoriamento remoto que, além de possibilitarem uma análise espacial das diferentes coberturas existentes no meio urbano e rural, também disponibilizam informações sobre a temperatura de superfície das diferentes coberturas terrestres a partir de sensores do infravermelho termal, como observado em pesquisas conduzidas por Streutker (2002), Yuan e Bauer (2006), Radhi et al. (2013), Yu et al. (2014), Trindade et al. (2017).

Atualmente, é possível adquirir imagens termais a partir do sensor TIRS a bordo do satélite Landsat 8 e esses produtos estão disponibilizados em resolução espacial de 30 metros (reamostradas) para coincidir com as demais bandas multiespectrais (bandas do visível e infravermelho próximo). Os 
problemas relacionados à calibração radiométrica do sensor TIRS devido a interferências de luz difusa foram solucionados para banda 10 termal a partir do algoritmo desenvolvido por Montanaro et al. (2015) que foi implementado nas imagens a partir do início de 2017 (GERACE \& MONTANARO, 2017).

Diante disso, estudos relacionados à temperatura nos ambientes urbanos e rurais dos municípios podem ser conduzidos a partir da análise da temperatura com a integração de dados de campo (pontuais) e imagens termais. Desta forma, parte-se da hipótese que a análise integrada do meio rural e urbano a partir de dados de campo e imagens orbitais para as quatro estações do ano possibilita diagnósticos das principais diferenças entre estes ambientes, bem como pode apontar as características mais relevantes.

Neste contexto, o objetivo da presente pesquisa foi verificar as diferenças térmicas entre o espaço urbano e o entorno rural de Santa Maria - RS no período de março/2017 a março/2018 a partir de pontos fixos de coletas de dados e imagens orbitais. Conforme Buriol et al. (2015), as condições meteorológicas na região de Santa Maria variam muito ao longo do ano e até mesmo ao longo do dia, o que exige uma rápida adaptação por parte dos seus habitantes. Neste sentido, pesquisas sobre a variação espacial e temporal da temperatura podem embasar mais estudos sobre as condições do conforto térmico nos municípios.

\section{MATERIAIS E MÉTODOS}

\subsection{LOCALIZAÇÃO DA ÁREA DE ESTUDO}

A pesquisa foi desenvolvida na área urbana e rural do município de Santa Maria localizado no centro do estado do Rio Grande do Sul (Figura 1). O município divide-se em 10 distritos (total de $1781 \mathrm{Km}^{2}$ ), 9 rurais e 1 distrito urbano. O perímetro urbano possui aproximadamente $126 \mathrm{Km}^{2}$ onde residem 95\% dos 261.000 habitantes (IBGE, 2018).

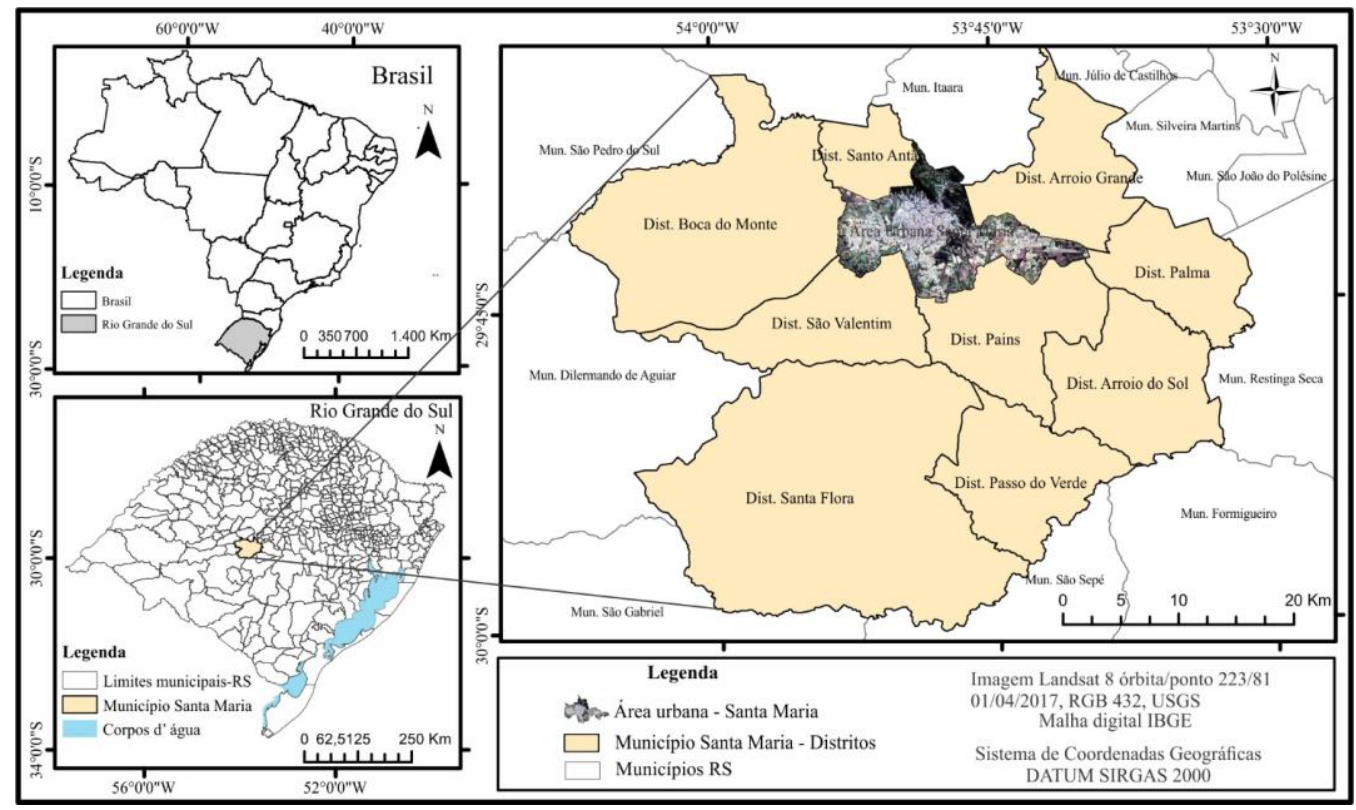

Figura 1- Localização da área de estudo Santa Maria - RS. 
Santa Maria apresenta três unidades geomorfológicas distintas: $1^{a}$ a Serra do Planalto Sul-Brasileiro com as maiores altitudes; $2^{a}$ o Rebordo do Planalto caracterizado pela transição entre o Planalto e a Depressão Periférica, apresentando vales e encostas íngremes; $3^{a}$ a Depressão Periférica, na qual se encontra a maior parte do município, caracterizada por colinas e planícies aluviais. A formação vegetal conta com os campos do bioma Pampa e florestas da Mata Atlântica (ROSS, 2001; SARTORI, 2009; MARCHIORI \& NOAL FILHO, 2009).

O clima é subtropical úmido com classificação Koppen Cfa, caracterizado por verões quentes com temperatura superior a $22^{\circ} \mathrm{C}$ no mês mais quente e precipitação média anual de 1600 a 1800 mm (BECK et al., 2018; ALVARES et al., 2014). Na classificação climática do Rio Grande do Sul definida por Rossato (2011), Santa Maria está inserida na classe Subtropical II caracterizado por clima mediamente úmido e com variação longitudinal das temperaturas médias. Neste sentido, destaca-se que o município foi escolhido por ser considerado um dos locais mais quentes do Rio Grande do Sul devido sua continentalidade e baixa altitude, apresentando temperatura próxima a $40^{\circ} \mathrm{C}$ entre novembro e março (HELDWEIN et al., 2009).

\subsection{PROCEDIMENTOS METODOLÓGICOS}

Para a realização da presente pesquisa foram utilizados os seguintes materiais: dados de campo que corresponderam aos registros de temperatura do ar em diferentes pontos distribuídos no meio urbano e rural de Santa Maria; dados de quatro imagens da plataforma Landsat 8; dados vetoriais - arquivos .shp com limites urbano e rural da área de estudo disponibilizados pelo IBGE; e software QGIS versão 2.14 para o processamento e representação dos dados. Os procedimentos metodológicos foram estabelecidos em três etapas principais: implantação de pontos fixos para coleta de dados (experimento de campo); processamento das imagens orbitais; e análise dos dados.

\subsubsection{IMPLANTAÇÃO DE PONTOS FIXOS PARA COLETA DE DADOS}

O experimento de campo correspondeu na aquisição de dados de temperatura do ar (Tar) a partir da implantação de 10 pontos fixos distribuídos na área de estudo. Neste sentido, foram adquiridos 10 data loggers denominados Tag Temp Stick que possuem um sensor interno medindo a temperatura ambiente (ar) e grava os valores em memória eletrônica. Os valores registrados podem ser enviados a um computador por meio do software LogCharte - II que é uma ferramenta utilizada para a configuração do registrador, por exemplo início e intervalo de tempo de aquisições de dados.

Segundo a Organização Meteorológica Mundial (OMM) a temperatura do ar pode ser medida por um termômetro exposto ao ar em um local protegido da incidência solar direta (WMO, 2008). Então, foi necessário o uso de abrigo para proteger o data logger da radiação direta, chuva e ventos fortes que poderiam danificá-lo. Com o custo elevado de abrigos meteorológicos, optou-se por construir um abrigo de baixo custo com base em modelos utilizados em estações meteorológicas automáticas e adaptados para o data logger adquirido para esta pesquisa. Os abrigos foram construídos seguindo o modelo 
disponibilizado pelo laboratório de Micrometeorologia da Universidade Federal de Santa Maria e adaptados conforme os materiais apresentados no Quadro 1.

Quadro 1 - Materiais utilizados na construção dos abrigos.

\begin{tabular}{|l|l|}
\hline \multicolumn{1}{|c|}{ Material } \\
\hline $\begin{array}{l}\text { Plafons brancos com proteção UV: para cada abrigo } \\
\text { foram utilizados } 8 \text { plafons, o primeiro foi adaptado com } \\
\text { uma válvula para lavatório que serviu para acomodar o } \\
\text { data logger dentro do abrigo. Os dois últimos foram } \\
\text { fechados. }\end{array}$ \\
$\begin{array}{l}\text { Barra roscada } 4 \mathrm{~mm} \text { de diâmetro: para cada abrigo } \\
\text { foram utilizadas } 2 \text { barras de } 25 \mathrm{~cm} \text { de comprimento. }\end{array}$ \\
$\begin{array}{l}\text { Roscas para barra roscada e arruelas: para cada abrigo } \\
\text { foram utilizadas } 40 \text { roscas e } 30 \text { arruelas. }\end{array}$ \\
\hline $\begin{array}{l}\text { Mangueira branca cortadas em } 1 \mathrm{~cm} \text { e } 5 \mathrm{~cm} \text { : para cada } \\
\text { abrigo foram utilizados } 14 \text { partes de } 1 \mathrm{~cm} \text { e } 2 \text { de } 4 \mathrm{~cm} \text {. }\end{array}$
\end{tabular}

Para o experimento de campo foram construídos 10 abrigos de $18 \mathrm{~cm}$ de altura cada, diâmetro externo de $13,5 \mathrm{~cm}$ e interno de $4,5 \mathrm{~cm}$ e os plafons foram separados a cada $1 \mathrm{~cm}$ (Figura 2a). Em cada abrigo foi anexado a um suporte que serviu para fixá-lo no local desejado, neste caso, em postes de madeira (Figura 2 b). Os abrigos ficaram a uma distância de 1,7 metros do solo, seguindo as normas de meteorologia (WMO, 2008) para instalação de estações meteorológicas.
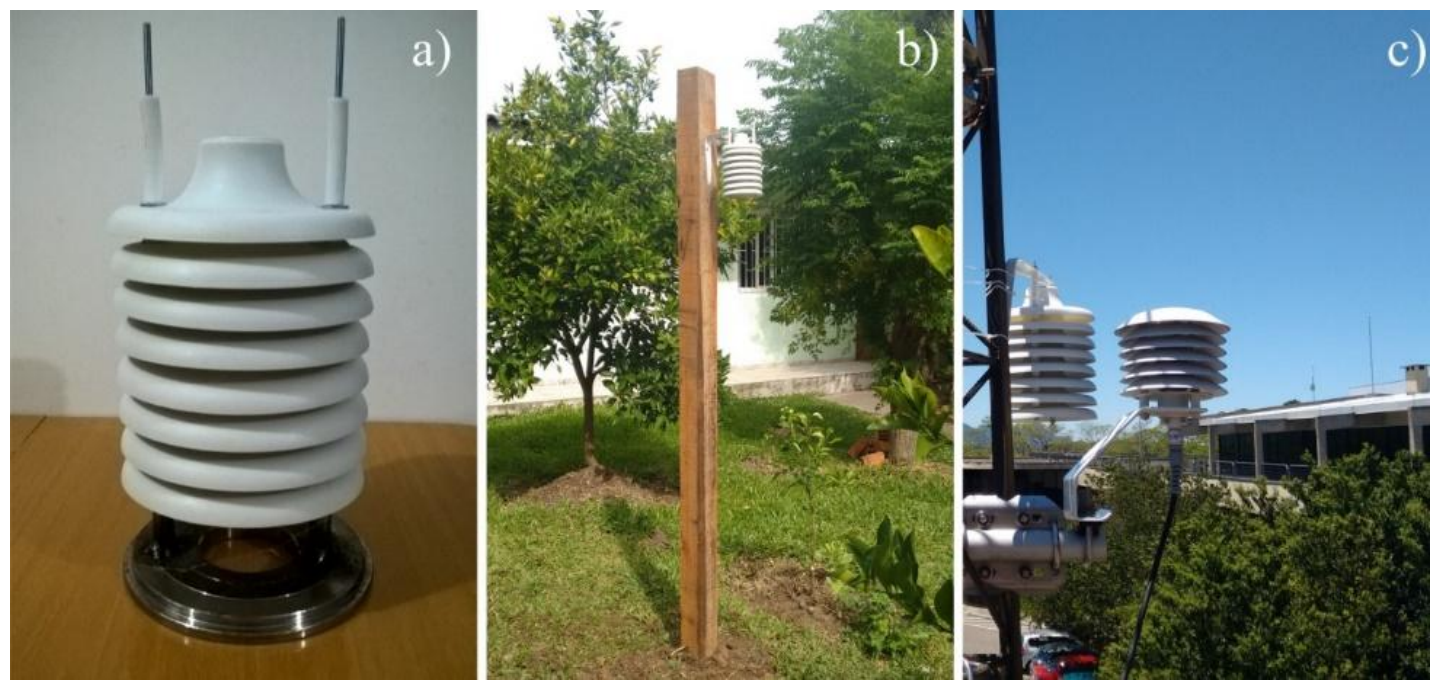
Figura 2 - Abrigo construído: a) abrigo pronto no suporte; b) abrigo instalado em campo; c) aferição entre abrigos.

Quanto à aferição da eficiência dos abrigos construídos, realizou-se a comparação entre os valores de temperatura registrados por dois data loggers adquiridos para esta pesquisa, um dentro do abrigo modelo e o outro no abrigo construído (Figura 2 c) em um período de 24 horas com intervalo de aquisição de 1 minuto. Sequencialmente, o erro médio absoluto (EMA) entre os registros foi calculado (Equação 1). O EMA é utilizado em situações de comparação de dados observados em campo e dados previstos por modelos, utilizado em trabalhos anteriores como Lopes et al. (2014), quanto mais próximo de zero o valor do EMA melhor o ajuste entre os dados.

$$
E M A=\frac{1}{N} \sum_{i=1}^{N} \mid X_{i}^{\prime}-X_{i}
$$

Onde: Xi - dados referência (data logger T1 no abrigo modelo); $\mathrm{Xi}^{\prime}$ - dados medidos (data logger T2 no abrigo construído); $\mathrm{N}$ - número pares de observações (1440 comparações).

Para a escolha dos locais em que os instrumentos seriam instalados (Figura 3) considerou-se 3 critérios: melhor distribuição espacial (regiões leste, oeste, norte, sul e centro); características da área (residencial com vegetação, residencial pouco arborizado e bairro centro-comercial); e questões relacionadas à segurança de cada local. Desta forma, foram instalados cinco data loggers em área urbana e cinco em área rural. As características de cada área podem ser observadas no Quadro 2.

Os dados foram coletados uma vez por estação e organizados de forma que facilitasse a extração de informações e análises. Os data loggers registraram a temperatura a cada 30 minutos, totalizando 48 registros por dia no período de março/2017 a março/2018, seguindo um intervalo de aquisição presente na pesquisa desenvolvida por Collischonn (2016).

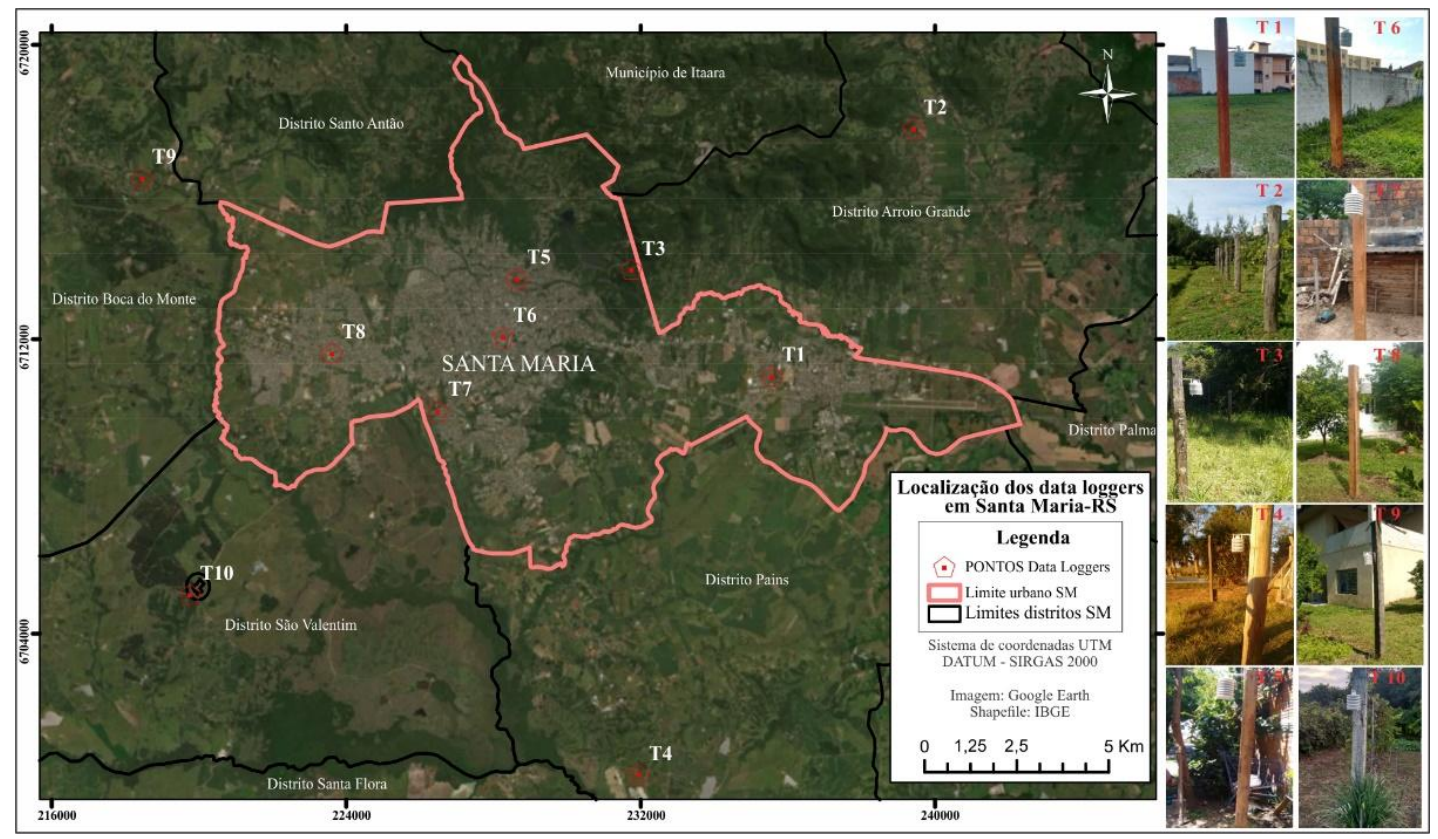

Figura 3 - Localização dos pontos de coleta de dados de temperatura. 
Quadro 2 - Característica dos pontos de coleta de dados de temperatura.

\begin{tabular}{|c|c|c|}
\hline Ponto & Localização & Características \\
\hline $\begin{array}{c}\text { T1 } \\
\text { urbano }\end{array}$ & Bairro Camobi, região leste. & $\begin{array}{l}\text { Residencial com pouca arborização e } \\
\text { próximo à edificação. Altitude } 108 \mathrm{~m} \text {. }\end{array}$ \\
\hline $\begin{array}{c}\mathrm{T} 2 \\
\text { rural }\end{array}$ & $\begin{array}{l}\text { Distrito Arroio } \\
\text { região nordeste. }\end{array}$ & $\begin{array}{l}\text { Propriedade com arborização e distante } \\
\text { de edificações. Altitude } 116 \mathrm{~m} \text {. }\end{array}$ \\
\hline $\begin{array}{l}\text { T3 } \\
\text { rural }\end{array}$ & $\begin{array}{l}\text { Bairro Campestre do Me } \\
\text { Deus, região nordeste. }\end{array}$ & $\begin{array}{l}\text { edade com arborização expressiva } \\
\text { ante de áreas construídas. Altitude }\end{array}$ \\
\hline $\begin{array}{l}\mathrm{T} 4 \\
\text { rural }\end{array}$ & $\begin{array}{l}\text { to } \\
\text { te. }\end{array}$ & $\begin{array}{l}\text { edade rural em local gramado e } \\
\text { esidências ao redor. Atitude } 74 \mathrm{~m} \text {. }\end{array}$ \\
\hline $\begin{array}{l}\text { T5 } \\
\text { urbano }\end{array}$ & Bairro Itararé, região n & arborização expressiva. \\
\hline $\begin{array}{c}\text { T6 } \\
\text { urbano }\end{array}$ & Bair & $\begin{array}{l}\text { ial com muitas edificações } \\
\text { de } 144 \mathrm{~m} \text {. }\end{array}$ \\
\hline $\begin{array}{c}\text { T7 } \\
\text { urbano }\end{array}$ & Bairro Urlândia, r & $\begin{array}{l}\text { Residencial com pouca arborização. } \\
\text { Altitude } 78 \mathrm{~m} .\end{array}$ \\
\hline $\begin{array}{c}\text { T8 } \\
\text { urbano }\end{array}$ & to Kubistchek, & $\begin{array}{l}\text { ncial, local gramado } \\
\text { zação. Atitude } 100 \mathrm{~m} \text {. }\end{array}$ \\
\hline $\begin{array}{l}\text { T9 } \\
\text { rural }\end{array}$ & $\begin{array}{l}\text { Distrito Boca do Monte, } \\
\text { região oeste). }\end{array}$ & $\begin{array}{l}\text { lo sem } \\
\mathrm{m} \text {. }\end{array}$ \\
\hline $\begin{array}{l}\text { T10 } \\
\text { rural }\end{array}$ & e. & $\begin{array}{l}\text { Propriedade rural, local gramado com } \\
\text { pouca arborização ao redor. Atitude } 145 \\
\text { m. }\end{array}$ \\
\hline
\end{tabular}

\subsubsection{PROCESSAMENTO DAS IMAGENS ORBITAIS}

As imagens orbitais consistiram em 4 produtos da plataforma Landsat 8 órbita/ponto 223/81 dos quais utilizaram-se as bandas do infravermelho termal em temperatura de brilho (Tbt - banda 10), do visível (bandas 2, 3, 4) e infravermelho próximo (banda 5) em reflectância de superfície, disponíveis na plataforma Earth Explorer (https://Ipcsexplorer.cr.usgs.gov/). Para a escolha das imagens considerou-se cenas sem nuvens e que estivessem distribuídas nas quatro estações do ano. Quanto maior o número de imagens mais completa ficaria a análise do trabalho, no entanto, a presença de nuvens comprometeu o estudo em muitas imagens. Assim, selecionou-se uma imagem para cada estação do ano: 01/04/2017 - outono, 07/08/017 - inverno, 11/11/2017 primavera, e 15/02/2018 - verão. O processamento das imagens foi realizado no software QGIS seguindo duas etapas principais: correção de imagens termais para temperatura de superfície e fatiamento das imagens em classes de temperatura.

A partir das imagens de temperatura de brilho é possível verificar a variação da temperatura em diferentes locais da imagem. No entanto a Tbt considera que todos os tipos de superfícies imageadas comportam-se como um corpo negro, ou seja, considera que a emissividade dos materiais é 1 . Sabe-se que na natureza, os diversos tipos e coberturas existentes não comportam-se 
como um corpo negro, então Van de Griend \& Owe (1993), Valor \& Caselles (1996) e Zhang et al. (2006) destacam a importância da correção das imagens com o valor de emissividade de cada alvo. Os processos de correção da imagem Tbt para temperatura de superfície (TS) foram realizados no QGIS, o qual apresenta o complemento Land Surface Temperatura (LST) desenvolvido por Ndossi \& Avdan (2016). O método de correção escolhido é denominado de "Planck Equation" (Equação 2) que considerada como dado de entrada imagem de Tbt e de emissividade.

A imagem de emissividade foi calculada no mesmo complemento com os valores de NDVI (Equação 3), metodologia desenvolvida por Zhang et al. (2006) e implementada no LST. Segundo Ndossi \& Avdan (2016), as imagens Landsat 8 corrigidas pelo método Planck Equation exibiram os melhores resultados quando comparadas com medidas de temperatura in situ. Assim, as imagens de saída foram de temperatura de superfície em graus celsius $\left({ }^{\circ} \mathrm{C}\right)$ posteriormente classificadas em 11 classes de temperatura. O intervalo entre as classes foi de $3^{\circ} \mathrm{C}$, pois também foi utilizado por Trindade et al. (2017) ao estudar ilhas de calor na área urbana de Santa Maria - RS.

$$
T S=\frac{T b t}{1+\left(\frac{\lambda T b t}{a}\right) * \ln \varepsilon}
$$

Onde $\mathrm{Tb}=$ temperatura de brilho ou aparente registrada pelo sensor em Kelvin; $\lambda=$ comprimento de onda médio do infravermelho termal;

$\mathrm{a}=\mathrm{hc} / \mathrm{K}=1.438 \times 10^{-2} \mathrm{~m} \mathrm{~K}$, onde:

$\mathrm{K}=$ constante de Stefan-Boltzman $\left(1.38 \times 10^{-23} \mathrm{~J} / \mathrm{K}\right)$

$\mathrm{h}=$ constante de Planck $\left(6.28 \times 10^{-34} \mathrm{~J} / \mathrm{s}\right)$

$\mathrm{c}=$ velocidade da luz $\left(2.998 \times 10^{8} \mathrm{~m} / \mathrm{s}\right)$

$\mathrm{In}_{\varepsilon}=$ logaritmo natural da emissividade da superfície.

$$
N D V I=\frac{\rho i v p-\rho v}{\rho i v p+\rho v}
$$

Onde, $\operatorname{\rho ivp}=$ reflectância no infravermelho próximo, $\rho v=$ reflectância no vermelho.

\subsubsection{ANÁLISE DOS DADOS}

As análises foram realizadas a partir de gráficos e cálculo de estatística descritiva dos dados coletados em campo e por imagem de satélite. Desta forma, foi possível comparar a distribuição da temperatura entre os pontos estudados, destacando as diferenças entre áreas urbanas e rurais e valores de temperatura de campo e orbitais.

\section{RESULTADOS E DISCUSSÃO}

Esta seção compreende a apresentação dos principais resultados obtidos na presente pesquisa que foram organizados em 4 seções: aferição dos abrigos para o experimento de campo; variação sazonal da temperatura do ar (março/2017 a março/2018); variação diária da temperatura do ar; e variação da temperatura de superfície. 


\subsection{AFERIÇÃO DOS ABRIGOS}

As estatísticas calculadas para os dados registrados no data logger/abrigo modelo foram similares às informações geradas no data logger/abrigo construído. O erro médio absoluto para a comparação não foi superior à $0,08^{\circ} \mathrm{C}$, apresentando resultado satisfatório para utilização dos abrigos. Como pode ser observado na Tabela 1, a diferença entre as médias dos dois abrigos foi de $0,01^{\circ} \mathrm{C}$, demostrando a eficiência dos materiais utilizados para a construção do abrigo para a presente pesquisa. Amorim et al. (2015) utilizaram material PVC na construção dos seus abrigos e os resultados encontrados demostraram similaridade com os dados registrados pela estação do Instituto Nacional de Meteorologia (INMET). Neste sentido, destaca-se que é possível utilizar materiais alternativos para a construção de abrigos meteorológicos eficientes e de baixo custo.

Tabela 1 - Estatística descritiva da temperatura nos data loggers em abrigos diferentes.

\begin{tabular}{ccc}
\hline $\begin{array}{c}\text { Tar } \\
{ }^{\circ} \mathrm{C}\end{array}$ & $\begin{array}{c}\text { Data logger/ } \\
\text { abrigo modelo }\end{array}$ & $\begin{array}{c}\text { Data logger/ } \\
\text { abrigo construído }\end{array}$ \\
\hline Máx & 32,40 & 32,40 \\
Mín & 12,50 & 12,50 \\
Média & 22,54 & 22,53 \\
Dpad & 6,14 & 6,19 \\
\hline
\end{tabular}

\subsection{VARIAÇÃO SAZONAL DA TEMPERATURA DO AR (março/2017 a março/2018)}

Em uma análise geral, verificou-se que a temperatura do ar nos pontos analisados variou de $11^{\circ} \mathrm{C}$ a $37^{\circ} \mathrm{C}$ em mais de 500 ocorrências para a série estudada (Figura 4). No entanto, em algumas áreas ocorreram temperaturas inferiores à $2^{\circ} \mathrm{C}$ e superiores à $42^{\circ} \mathrm{C}$, fato explicado pelas diferentes características espaciais de cada ponto de registro. 


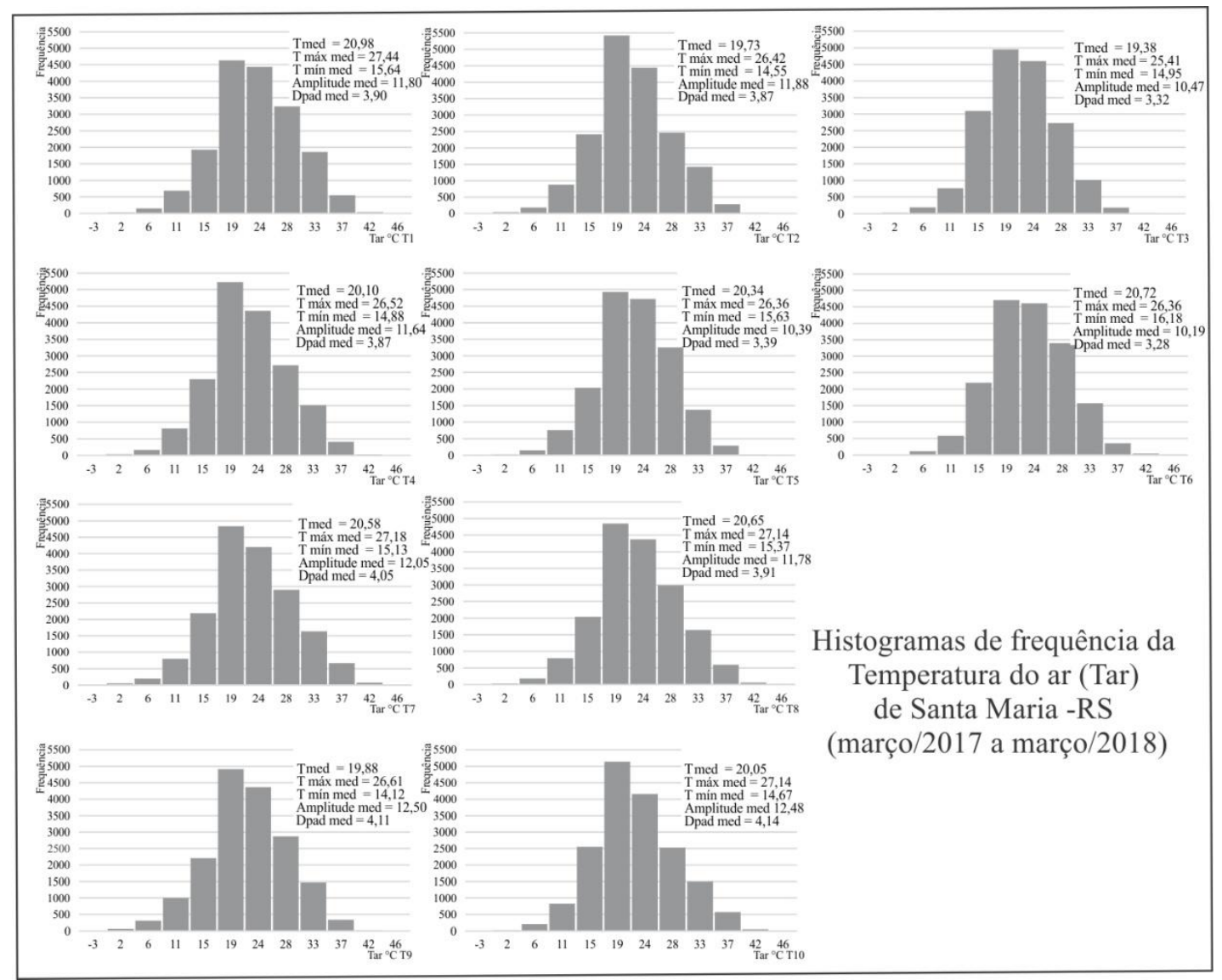

Figura 4 - Histogramas de frequência da temperatura do ar de cada ponto durante o período março/2017 a março/2018.

O intervalo de maior ocorrência para todos os pontos correspondeu à temperatura de $18^{\circ} \mathrm{C}$ a $23^{\circ} \mathrm{C}$. A variação diária da temperatura (amplitude térmica diária) apresentou valor médio anual de $11^{\circ} \mathrm{C}$, com as menores amplitudes na estação de inverno e maiores no verão o que reitera as afirmações de Heldwein et al. (2009).

A temperatura média dos pontos localizados em área urbana (T1, T5, T6, T7 e T8) foi de $20,6^{\circ} \mathrm{C}$, com destaque para os pontos T1 (residencial sem arborização) e T5 (residencial com densa arborização) que registraram maior e menor temperatura média respectivamente. Nos pontos localizados em área rural (T2, T3, T4, T9 e T10) a temperatura média foi de $19,8^{\circ} \mathrm{C}$, sendo os menores valores registrados em T3 (maior altitude e com densa vegetação) e maiores em T4 (área com vegetação rasteira e períodos de solo exposto). Cabe destacar que no ponto T3 a média das máximas foi a menor, o que pode ser explicado pelas características diferenciadas do local com arborização expressiva e maior altitude (região norte da cidade). Neste caso, o cenário encontrado reitera o que foi descrito por Sartori (2016), que os valores mais baixos de temperatura são registrados ao norte de Santa Maria, área localizada no Planalto Meridional Brasileiro, as temperaturas mais altas são observadas na área da Depressão Periférica, onde a maior parte da área urbana está inserida. 
Ao analisar a variação da temperatura para a estação do outono nos pontos localizados em área urbana, verificou-se que os valores aproximados das médias ficaram entre $17^{\circ} \mathrm{C}$ e $18^{\circ} \mathrm{C}$, com mínimas entre $12^{\circ} \mathrm{C}$ e $14^{\circ} \mathrm{C}$ e máximas de $22^{\circ} \mathrm{C}$ a $23^{\circ} \mathrm{C}$ (Tabela 2 ). As localidades rurais apresentaram temperaturas médias aproximadas entre $16^{\circ} \mathrm{C}$ e $17^{\circ} \mathrm{C}$, com valores mínimos de $12^{\circ} \mathrm{C}$ a $13^{\circ} \mathrm{C}$ e máximos de $21^{\circ} \mathrm{C}$ a $23^{\circ} \mathrm{C}$. Os pontos rurais apresentaram amplitude térmica (média) superior à amplitude dos pontos urbanos, entretanto, a diferença entre as temperaturas médias dos dois ambientes foi de $0,5^{\circ} \mathrm{C}$ (urbano $-17,91^{\circ} \mathrm{C}$ e rural $\left.-17,37^{\circ} \mathrm{C}\right)$.

Tabela 2 - Temperatura do ar (média, média das mínimas, médias das máximas e amplitude térmica média) para a estação outono/2017.

\begin{tabular}{lrrrrrrrrrr}
\hline Tar $\left({ }^{\circ} \mathrm{C}\right)$ & \multicolumn{1}{c}{ T1 } & \multicolumn{1}{c}{ T2 } & \multicolumn{1}{c}{ T3 } & \multicolumn{1}{c}{ T4 } & \multicolumn{1}{c}{ T5 } & \multicolumn{1}{c}{ T6 } & \multicolumn{1}{c}{ T7 } & \multicolumn{1}{c}{ T8 } & \multicolumn{1}{c}{ T9 } & T10 \\
\hline Média & 18,30 & 17,40 & 16,75 & 17,74 & 17,75 & 17,89 & 17,82 & 17,80 & 17,48 & 17,47 \\
Média máx & 23,75 & 22,98 & 21,54 & 23,36 & 22,39 & 22,45 & 22,80 & 22,88 & 23,24 & 23,24 \\
Média mín & 14,18 & 13,31 & 13,47 & 13,75 & 14,20 & 14,51 & 13,88 & 13,91 & 12,96 & 13,47 \\
Amplitude & 9,57 & 9,67 & 8,07 & 9,61 & 8,19 & 7,94 & 8,92 & 8,98 & 10,27 & 9,78 \\
\hline
\end{tabular}

De forma geral, a maioria dos pontos apresentou 47 dias com temperaturas superiores às médias das máximas. Em constatações mais pontuais, verificou-se que a maior temperatura média e média das máximas ocorreu no ponto T1, localizado em área urbana próximo às edificações e sem arborização. Em contrapartida, os menores valores de temperatura média e média das máximas foram registrados em T3 caracterizado por expressiva arborização, distante de áreas construídas e localizado em altitude mais elevada que os demais. O ponto $\mathrm{T} 1$ apresentou a maior diferença quando comparado com a média dos pontos rurais, sendo superior em $0,93^{\circ} \mathrm{C}$ a $4,3^{\circ} \mathrm{C}$. O ponto T5 foi o que apresentou a menor diferença em relação a temperatura média dos pontos rurais, com valor superior em $0,38^{\circ} \mathrm{C}$. Quando os dados dos pontos urbanos foram comparados com o ponto T3, localizado em área bastante arborizada e em altitude maior, verificou-se que as diferenças foram ainda mais significativas, em relação a T1 a diferença média foi de $1,5^{\circ} \mathrm{C}$.

Assim como no outono, o inverno também apresentou temperatura média entre $17^{\circ} \mathrm{C}$ e $18^{\circ} \mathrm{C}$ e média das mínimas de $12^{\circ} \mathrm{C}$ a $14^{\circ} \mathrm{C}$ para as localidades urbanas. Em contrapartida as médias das máximas foram superiores nesta estação, próximas a $24^{\circ} \mathrm{C}$ e $25^{\circ} \mathrm{C}$ (Tabela 3 ). Tal fato pode ser justificado pela ocorrência de registros de temperatura superiores à $35^{\circ} \mathrm{C}$ em alguns dias da estação. Para os pontos localizados em área rural a temperatura média ficou próxima dos $17^{\circ} \mathrm{C}$, com intervalos de mínima entre $11^{\circ} \mathrm{C}$ e $13^{\circ} \mathrm{C}$ e máxima de $23^{\circ} \mathrm{C}$ a $24^{\circ} \mathrm{C}$.

Tabela 3 - Temperatura do ar (média, média das mínimas, média das máximas e amplitude térmica média) para a estação inverno/2017.

\begin{tabular}{cccrccccccc}
\hline Tar $\left({ }^{\circ} \mathrm{C}\right)$ & T1 & \multicolumn{1}{c}{ T2 } & \multicolumn{1}{c}{ T3 } & T4 & T5 & T6 & T7 & T8 & T9 & T10 \\
\hline Média & 18,62 & 17,51 & 17,89 & 17,22 & 17,99 & 18,29 & 17,56 & 17,81 & 17,49 & 17,37 \\
Média máx & 25,21 & 24,19 & 23,57 & 23,57 & 24,10 & 24,11 & 24,20 & 24,16 & 24,62 & 24,52 \\
Média mín & 13,32 & 12,46 & 13,69 & 12,00 & 13,18 & 14,05 & 12,14 & 12,72 & 11,53 & 12,13 \\
Amplitude & 11,89 & 11,73 & 9,88 & 11,58 & 10,92 & 10,06 & 12,06 & 11,44 & 13,09 & 12,38 \\
\hline
\end{tabular}

Diferente do outono, 0 inverno apresentou dias com temperaturas superiores a $35^{\circ} \mathrm{C}$ e inferiores a $5^{\circ} \mathrm{C}$, justificando também sua amplitude térmica 
superior ao outono. As temperaturas médias e máximas mais elevadas foram registradas na área urbana, no ponto T1. As menores temperaturas ocorreram em área rural, nos pontos T4 e T3. A diferença entre as temperaturas médias do urbano e rural foi de $0,5^{\circ} \mathrm{C}$, com maior média ainda nos pontos urbanos. Ao comparar todos os pontos urbanos com a média dos pontos rurais, constatou-se que a maior diferença foi registra entre $\mathrm{T} 1$ e os pontos rurais, apresentando temperatura superior em até $1,12^{\circ} \mathrm{C}$, as menores diferenças foram encontradas nos pontos T7 e T8.

Na primavera, como o esperado, as temperaturas apresentaram-se mais elevadas em relação às estações de outono e inverno (Tabela 4). Nos pontos localizados em área urbana, as temperaturas médias ficaram entre $21^{\circ} \mathrm{C}$ e $22^{\circ} \mathrm{C}$, média das mínimas de $15^{\circ} \mathrm{C}$ a $16^{\circ} \mathrm{C}$ e máximas de $27^{\circ} \mathrm{C}$ a $29^{\circ} \mathrm{C}$. Nas áreas rurais os valores de temperatura registrados na primavera também foram inferiores aos da área urbana e as temperaturas médias foram de $20^{\circ} \mathrm{C}$ a $21^{\circ} \mathrm{C}$, com mínimas de $14^{\circ} \mathrm{C}$ a $15^{\circ} \mathrm{C}$ e máximas de $26^{\circ} \mathrm{C}$ a $28^{\circ} \mathrm{C}$. A amplitude térmica dos dois ambientes foi próxima, com diferença de $0,3^{\circ} \mathrm{C}$, no entanto, a diferença entre as médias dos pontos rurais e urbanos foi de $1,06^{\circ} \mathrm{C}$, apresentando a maior diferença em relação ao outono e inverno.

Tabela 4 - Temperatura do ar (média, média das mínimas, média das máximas e amplitude térmica média) para a estação primavera/2017.

\begin{tabular}{ccccccccccc}
\hline Tar $\left({ }^{\circ} \mathrm{C}\right)$ & T1 & T2 & T3 & T4 & T5 & T6 & T7 & T8 & T9 & T10 \\
\hline Média & 22,12 & 20,73 & 20,08 & 21,24 & 21,44 & 21,91 & 21,96 & 22,05 & 20,91 & 21,25 \\
Média máx & 28,90 & 27,72 & 26,81 & 27,75 & 27,53 & 27,80 & 29,18 & 29,17 & 27,82 & 28,69 \\
Média mín & 16,16 & 15,02 & 15,00 & 15,57 & 16,11 & 16,69 & 15,77 & 16,02 & 14,72 & 15,16 \\
Amplitude & 12,74 & 12,70 & 11,81 & 12,18 & 11,41 & 11,11 & 13,41 & 13,15 & 13,10 & 13,53 \\
\hline
\end{tabular}

As temperaturas mais elevadas foram, novamente, verificadas em áreas urbanas. A maior temperatura média foi registrada em T1 e maiores médias das máximas em T7 e T8. Os menores valores de temperatura média e média das máximas foram registrados em T3, maior altitude e arborizado. Comparando-se os valores de temperatura dos pontos urbanos e a média dos rurais, identificouse que as diferenças variaram de $1,28^{\circ} \mathrm{C}$ ( $\mathrm{T} 1 \times$ Trurais) e $0,6^{\circ} \mathrm{C}$ (T5 $\mathrm{x}$ Trurais). No primeiro caso, a maior diferença deve-se ao fato de T1 estar localizado em área urbana com muitas residências, no segundo caso, T5 está localizado em área urbana com arborização. Quando verificadas as diferenças dos pontos urbanos em relação apenas a T3, identificou-se que as diferenças foram ainda maiores, superiores a $2^{\circ} \mathrm{C}$ em $\mathrm{T} 1$.

A temperatura média para a estação do verão no meio urbano concentrou-se no intervalo de $24^{\circ} \mathrm{C}$ a $25^{\circ} \mathrm{C}$, com média das mínimas de $18^{\circ} \mathrm{C}$ a $19^{\circ} \mathrm{C}$ e média das máximas próximas a $30^{\circ} \mathrm{C}$ e $32^{\circ} \mathrm{C}$ (Tabela 5). Nos pontos localizados em áreas rurais a temperatura média variou entre $23^{\circ} \mathrm{C}$ e $24^{\circ} \mathrm{C}$, média das máximas de $29^{\circ} \mathrm{C}$ a $32^{\circ} \mathrm{C}$ e média das mínimas entre $17^{\circ} \mathrm{C}$ e $18^{\circ} \mathrm{C}$. Nesta estação foram verificados os maiores valores de amplitude térmica nos pontos urbanos e rurais, bem como a maior diferença entre as temperaturas médias destes dois ambientes $\left(1,17^{\circ} \mathrm{C}\right)$. 
Tabela 5 - Temperatura do ar (média, média das mínimas, média das máximas e amplitude térmica média) para a estação verão/2017-2018.

\begin{tabular}{ccccccccccc}
\hline Tar $\left({ }^{\circ} \mathrm{C}\right)$ & T1 & T2 & T3 & T4 & T5 & T6 & T7 & T8 & T9 & T10 \\
\hline Média & 25,11 & 23,49 & 23,01 & 24,40 & 24,42 & 25,03 & 25,23 & 25,18 & 23,85 & 24,36 \\
Média máx & 32,16 & 31,05 & 29,98 & 31,68 & 30,34 & 31,36 & 32,85 & 32,67 & 31,02 & 32,41 \\
Média mín & 19,08 & 17,55 & 17,76 & 18,37 & 19,21 & 19,63 & 18,92 & 19,00 & 17,41 & 18,07 \\
Amplitude & 13,07 & 13,50 & 12,22 & 13,32 & 11,12 & 11,73 & 13,94 & 13,66 & 13,60 & 14,35 \\
\hline
\end{tabular}

A maior temperatura média e média das máximas ocorreu no ponto T7 (urbano residencial). A maior média das temperaturas mínimas foi registrada em T6 (centro-comercial). Em contrapartida, os menos valores de temperatura média e média das máximas foram registrados em T3 (rural com arborização e maior altitude). Assim como nas demais estações, verificou-se que as diferenças entre os pontos urbanos e rurais ainda continuaram superiores quando verificados $\mathrm{T} 1$ e a média do rural, em relação a T3 chegou até $2,10^{\circ} \mathrm{C}$ de diferença.

Diante do exposto, pode-se dizer que a temperatura do ar foi mais elevada em área urbana em todas as estações do ano, com maiores diferenças no verão. Neste caso, comprova-se o quanto a presença de vegetação pode contribuir para a amenização da temperatura nas áreas urbanas, fato que deve ser levado em consideração pelos gestores públicos. De acordo com Alves (2012), quanto ao crescimento das cidades de porte médio, Santa Maria é exemplo em que a vegetação urbana é suprimida para dar lugar às edificações.

\subsection{VARIAÇÃO DIÁRIA DA TEMPERATURA DO AR}

$\mathrm{Na}$ estação do outono as menores temperaturas, de modo geral, ocorreram próximo às 7:00 da manhã e as mais elevadas foram verificadas às 15:00 da tarde (Figura 5 - a). Dentre os pontos urbanos, o T6 registrou valores mais elevados que os demais nos períodos da madrugada e noite (ilhas de calor - região central) e o T1 no período da manhã e tarde. Em relação aos pontos das áreas rurais, o T4 registrou os maiores valores nos períodos da madrugada, tarde e noite, e T9 no período da manhã.

Assim como no outono, as temperaturas mínimas e máximas no inverno também foram registradas às 7:00 e 15:00 respectivamente, do mesmo modo as maiores temperaturas foram verificadas nos pontos urbanos (Figura $5-b$ ). Em relação à área urbana, os valores mais elevados para os períodos da madrugada e noite foi em T6 (ilhas de calor - região central), e no período da manhã e tarde em T1. Dentre os pontos das áreas rurais, o T3 registrou os maiores valores nos períodos da madrugada, manhã e noite, e T9 na tarde.

$\mathrm{Na}$ estação da primavera as menores temperaturas foram registradas, de modo geral, uma hora antes das estações do outono e inverno, às 6:00 da manhã, mas os valores mais elevados continuaram a ser verificados no período da tarde, próximo às 15:00 (Figura 5 - c). O ponto T6 registrou valores mais elevados que os demais nos períodos da noite e madrugada (ilhas calor - região central), o T1 no período da manhã e T7 no da tarde. Nas áreas rurais, o T4 registrou os maiores valores nos períodos da madrugada e noite, e T9 e T10 nos períodos da manhã e tarde, respectivamente. 
A estação do verão, assim como na primavera, apresentou valores de temperatura máxima próximo às 15:00 e temperaturas mínimas às 6:00 da manhã (Figura 5 - d). Na área urbana, o ponto T6 registrou valores mais elevados que os demais nos períodos da madrugada e noite (ilhas calor - região central), o T1 no período da manhã e T7 no da tarde. Em relação aos pontos das áreas rurais, o T4 registrou os maiores valores nos períodos da madrugada e noite, e T9 e T10 nos períodos da manhã e tarde, respectivamente.

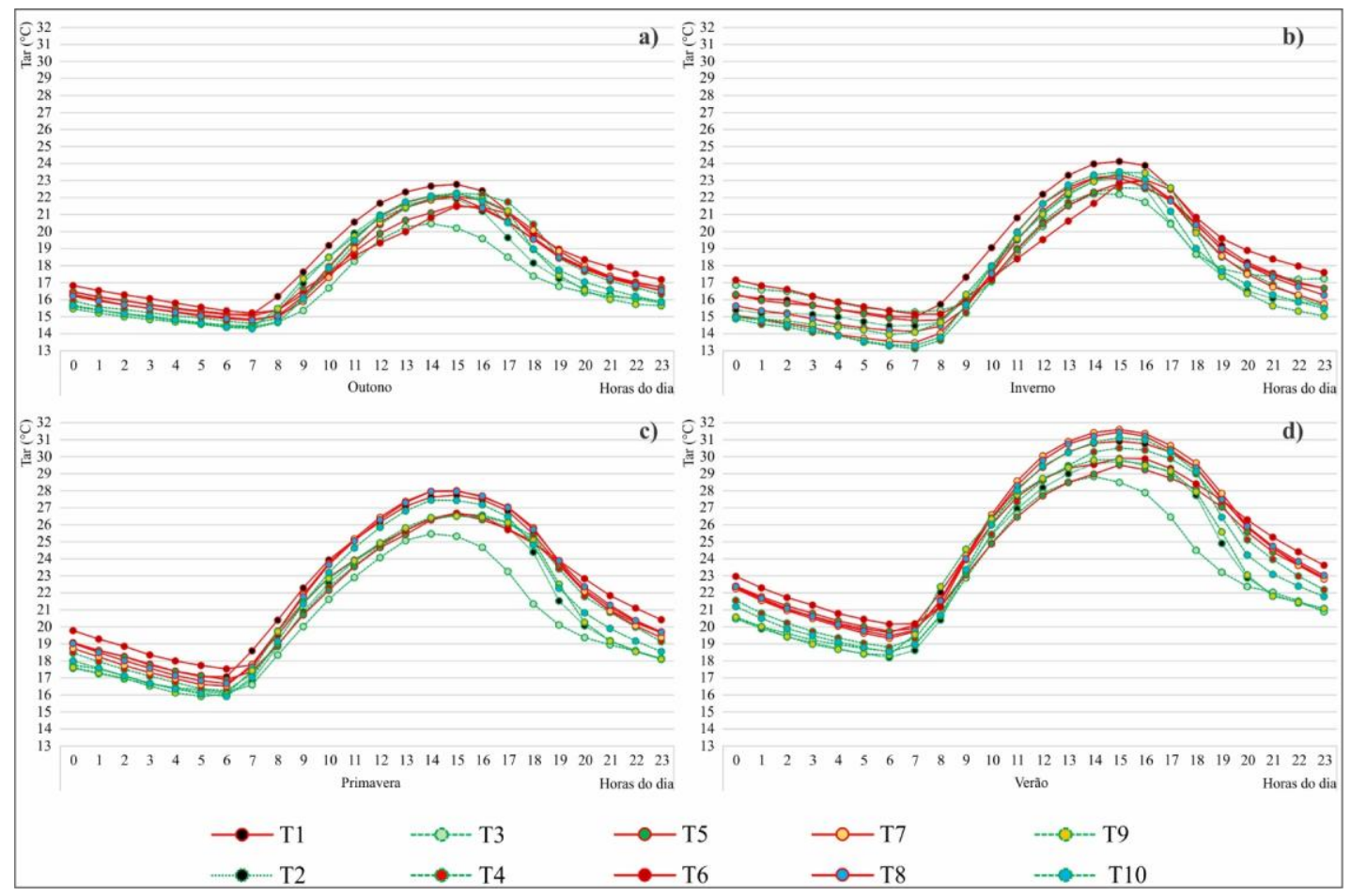

Figura 5 - Temperatura do ar média para cada período do dia de março/2017 a março/2018 em Santa Maria - RS: a) variação diária da temperatura no outono; b) variação diária da temperatura no inverno; c) variação diária da temperatura na primavera; d) variação diária da temperatura no verão.

De modo geral, pode-se dizer que em todas as estações do ano a temperatura em áreas urbanas foi superior do que as rurais, em contrapartida, nas estações mais quentes as diferenças foram mais significativas. No período da madrugada, a temperatura média na área urbana chegou a ser até $1,45^{\circ} \mathrm{C}$ superior às áreas rurais no verão, na primavera a diferença foi de $1,06^{\circ}$, no inverno de $0,55^{\circ}$ e outono $0,70^{\circ} \mathrm{C}$. No período da noite, a média da temperatura no ambiente rural foi menor $1,91^{\circ} \mathrm{C}$ que o urbano no verão e na primavera a diferença foi de $1,54^{\circ} \mathrm{C}$, no outono e inverno essa diferença foi, no máximo, $1,07^{\circ} \mathrm{C}$. Nos períodos da manhã e tarde as diferenças entre as médias do urbano e rural foram, no máximo, até $0,85^{\circ} \mathrm{C}$ para primavera e verão, e não ultrapassam $0,33^{\circ} \mathrm{C}$ no outono e inverno.

Desta forma, foi possível pontuar dois aspectos interessantes, quanto às características de T6 e T3. O ponto T6, localizado em área centro-comercial, apresentou características de ilhas de calor urbanas, ou seja, maior aquecimento que os demais pontos durante a noite e madrugada. Conforme Oke (1978), ao substituir superfícies com vegetação por superfícies impermeáveis ocorre uma modificação do balanço energético nas cidades, ocasionado o 
aprisionamento da radiação. Neste caso, a temperatura continua mais elevada nas áreas centrais após o pôr do sol, configurando ilhas de calor urbanas. No trabalho realizado por Collischonn (2016), foi encontrada uma diferença de $5,4^{\circ} \mathrm{C}$ entre as áreas centrais e periféricas de Pelotas para o período noturno.

O ponto T3, localizado em maior altitude e com densa arborização, apresentou as menores temperaturas no período da tarde, entretanto no inverno a temperatura foi superior aos demais pontos no período da manhã. Esta ocorrência pode ser justificada pelo fato que no inverno os dias com nevoeiro são mais frequentes e como o T3 foi instalado em maior altitude ficou livre deste fenômeno durante a manhã, enquanto os demais pontos estavam sob influência da condição meteorológica citada, justificando a maior temperatura em T3. De acordo com Heldwein et al. (2009) a disponibilidade da radiação solar na cidade é uma das menores do estado do Rio Grande do Sul e ocorrem elevada frequência de nevoeiros, aproximadamente, 92 dias por ano.

\subsection{VARIAÇÃO DA TEMPERATURA DE SUPERFÍCIE (imagens termais)}

Para a análise da temperatura de superfície (TS) foram consideradas quatro imagens termais, uma para cada estação do ano para o período estudado. Neste sentido, na imagem do outono (Figura 6 - a) os valores de TS variaram de $17^{\circ} \mathrm{C}$ a $35^{\circ} \mathrm{C}$. No entanto, o intervalo de $23^{\circ} \mathrm{C}$ a $26^{\circ} \mathrm{C}$ predominou em $50 \%$ da área estudada. Comparando-se áreas urbanas e rurais (Figura 6 Gráficos 2 e 3), verificou-se o predomínio das classes $23^{\circ} \mathrm{C}$ a $26^{\circ} \mathrm{C}$ e $26^{\circ} \mathrm{C}$ a $29^{\circ} \mathrm{C}$, no entanto, a primeira classe ocorreu com maior frequência no rural (mais de $50 \%$ ) e a segunda, maior TS, no urbano (30\%). 

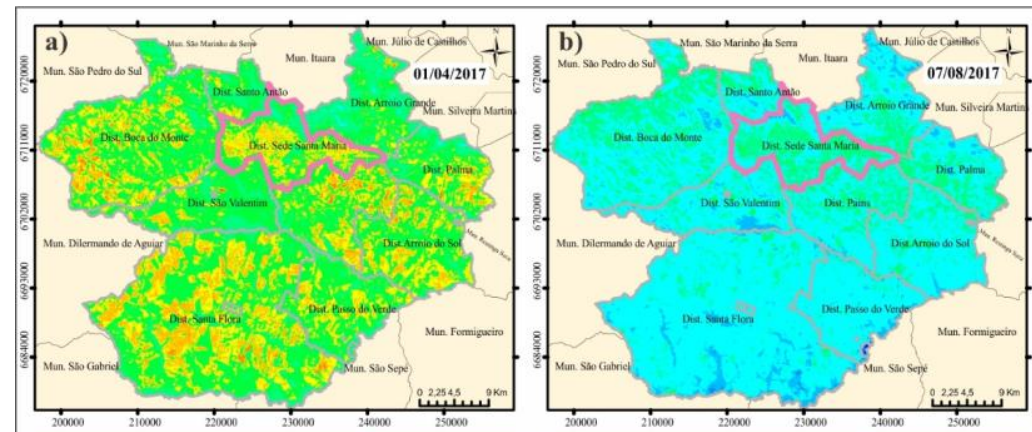

Temperatura de superfície (TS) de Santa Maria - RS
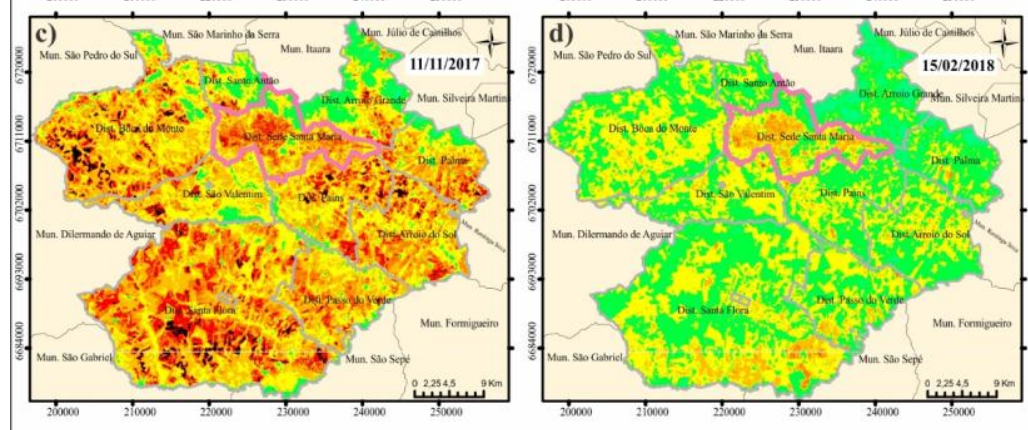

Legenda

Classes TS $\left({ }^{\circ} \mathrm{C}\right)$
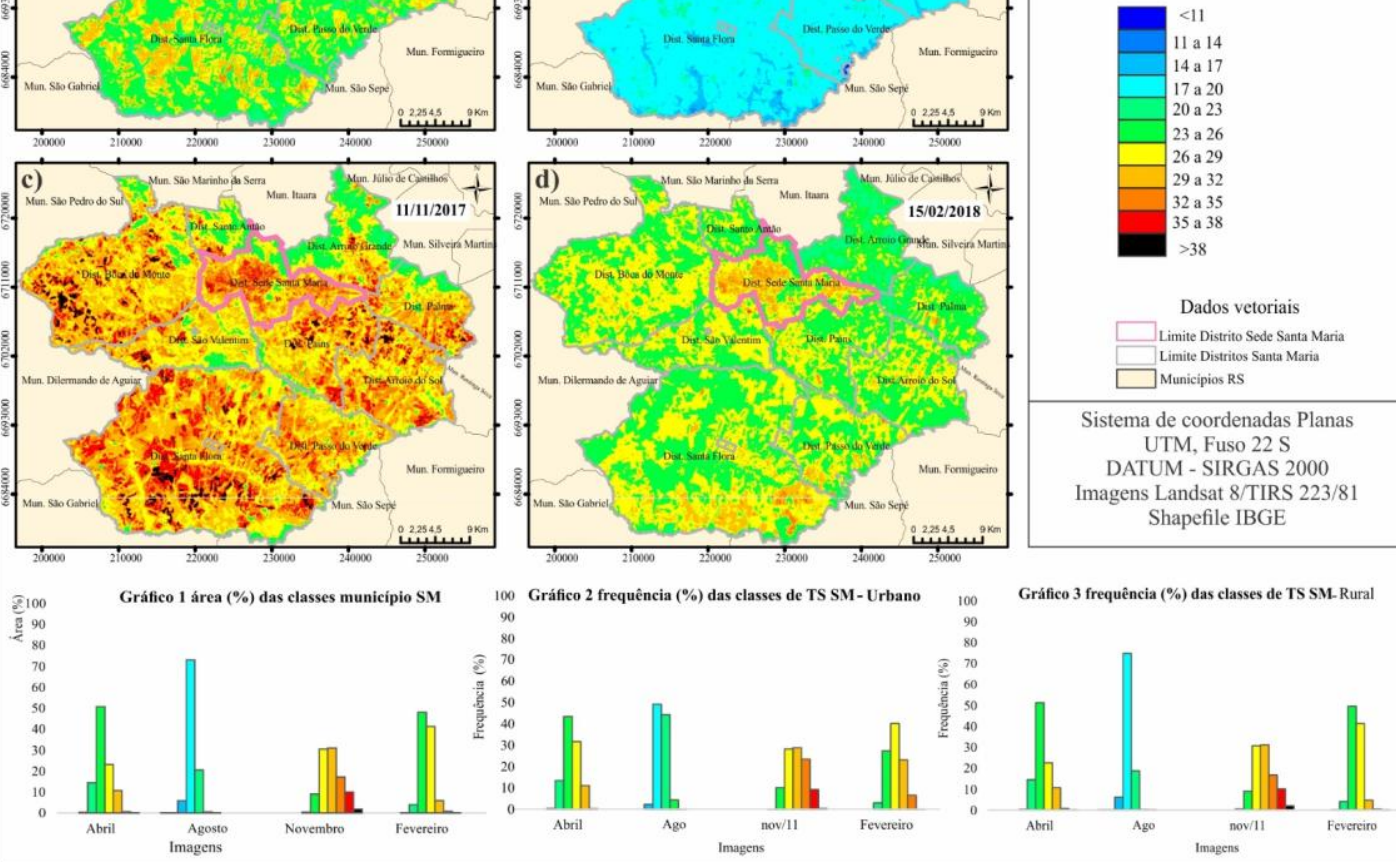

Figura 6 - Temperatura de Superfície para as imagens: a) 01/04/2017; b) 07/08/2017; c) $11 / 11 / 2017$; d) $15 / 02 / 2018$.

$\mathrm{Na}$ imagem do inverno (Figura 6 - b), constatou-se que os valores que mais ocorreram compreenderam o intervalo de $14^{\circ} \mathrm{C}$ a $23^{\circ} \mathrm{C}$. Tanto em áreas urbanas quanto rurais, verificou-se o predomínio das classes $17^{\circ} \mathrm{C}$ a $20^{\circ} \mathrm{C}$ e $23^{\circ} \mathrm{C}$ a $26^{\circ} \mathrm{C}$, porém, constatou-se que a primeira classe ocorreu com maior frequência no rural (mais de $70 \%$ ) e a segunda (maior temperatura) no urbano (mais de $40 \%$ ).

$\mathrm{Na}$ imagem da primavera (Figura 6 - c), verificou-se o predomínio da classe de $29^{\circ} \mathrm{C}$ a $32^{\circ} \mathrm{C}(30,94 \%)$, seguida da classe $26^{\circ} \mathrm{C}$ a $29^{\circ}$ em $30,45 \%$ da área. Para esta imagem, não verificou-se muitas diferenças entre a TS de áreas urbanas e rurais, entretanto, ocorreu um aumento da classe de $32^{\circ} \mathrm{C}$ a $35^{\circ} \mathrm{C}$ nas áreas urbanas e temperaturas maiores que $38^{\circ} \mathrm{C}$ em áreas rurais. Este fato pode ser justificado pela ocorrência de solo exposto nas áreas rurais para esta época do ano, já que este uso assemelha-se ao comportamento espectral de áreas construídas.

$\mathrm{Na}$ imagem do verão (Figura 6 - d), constatou-se valores de TS variando entre $20^{\circ} \mathrm{C}$ a $35^{\circ} \mathrm{C}$ e as temperaturas que mais ocorreram foram entre $23^{\circ} \mathrm{e}$ $32^{\circ} \mathrm{C}$, com predomínio das classes $23^{\circ} \mathrm{C}$ a $26^{\circ} \mathrm{C}(48 \%)$ e $26^{\circ} \mathrm{C}$ a $29^{\circ} \mathrm{C}(41,20 \%)$. Ao comparar a TS em áreas urbanas e rurais, verificou-se que no urbano a classe $26^{\circ} \mathrm{C}$ a $29^{\circ} \mathrm{C}$ ocorreu com maior frequência (40\%), no rural foi classe $23^{\circ} \mathrm{C}$ a $26^{\circ} \mathrm{C}(50 \%)$. 
Ao comparar a temperatura de superfície (TS) e temperatura do ar (Tar) para as datas e horário das imagens, constatou-se que na maioria dos pontos TS foi superior que Tar e as maiores diferenças foram verificadas nos pontos localizados em área urbana (Figura 7). As menores diferenças foram encontradas nos pontos rurais, configurando, em alguns casos, Tar superiores que TS. De modo geral, a diferença média entre TS e Tar foi de $3,2^{\circ} \mathrm{C}$, com mínima de $0,08^{\circ} \mathrm{C}$ no inverno (área rural) e máxima de $9,65^{\circ} \mathrm{C}$ na primavera (área urbana). Em estudo anterior, ao comparar as temperaturas do ar e de superfície em diferentes áreas, Guan (2011) verificou diferenças $8^{\circ} \mathrm{C}$ a $15^{\circ} \mathrm{C}$ para áreas construídas e diferenças inferiores a $1^{\circ} \mathrm{C}$ em áreas com gramado.

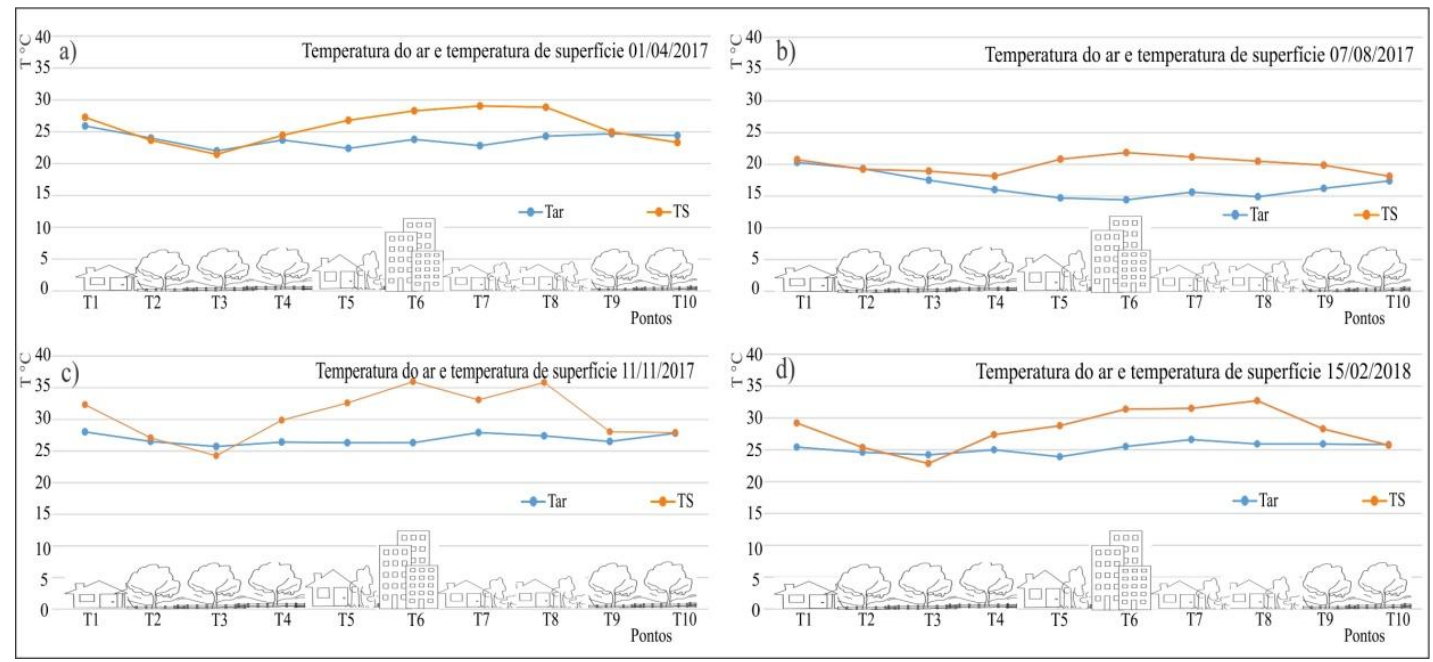

Figura 7 - Comparação entre temperatura do ar (Tar) e temperatura de superfície (TS) em cada ponto. a) 01/04/2017; b) 07/08/2017; c) $11 / 11 / 2017$; d)15/02/2018.

Para a imagem do outono, constatou-se que a diferença média entre as temperaturas TS e Tar foi de, aproximadamente, $2,40^{\circ} \mathrm{C}$ e a diferença máxima $\left(6,24^{\circ} \mathrm{C}\right)$ foi no ponto $\mathrm{T} 7$ (localizado em área urbana) e mínima de $0,27^{\circ} \mathrm{C}$ no ponto T9, área rural, (Figura $7-\mathrm{a}$ ). Na imagem no inverno, verificou-se que a diferença média entre TS e Tar foi de $3,32^{\circ} \mathrm{C}$, com diferença máxima de $7,45^{\circ} \mathrm{C}$ no ponto T6 e mínima $\left(0,08^{\circ} \mathrm{C}\right.$ ) no T2 (Figura $7-\mathrm{b}$ ). Em relação à imagem da primavera, as diferenças entre TS e Tar foram maiores, com média de $4,10^{\circ} \mathrm{C}$ de diferença, mínima de $0,12^{\circ} \mathrm{C}$ no T10 e máxima de $9,65^{\circ} \mathrm{C}$ no T6 (Figura 7 c). $\mathrm{Na}$ imagem do verão, constatou-se que a média das diferenças entre TS e Tar foi de $3,32^{\circ} \mathrm{C}$, a diferença mínima foi no ponto $\mathrm{T} 10\left(0,10^{\circ} \mathrm{C}\right)$ e a máxima no ponto $\mathrm{T} 8\left(6,80^{\circ} \mathrm{C}\right)$.

Pode-se dizer que os resultados obtidos nas imagens reiteram as análises realizadas a partir dos data loggers distribuídos na área de estudo, pois também constatou-se temperatura mais elevada na área urbana, principalmente onde a vegetação não predominou. Em relação às diferenças entre os dados de campo e das imagens, pode-se verificar que em áreas mais homogêneas, caso das áreas rurais, as diferenças foram menores em relação aos dados do urbano. Cenário semelhante foi constatado por Norman e Becker (1995) os quais relatam que a temperatura obtida através de imagens é altamente correlacionada a temperatura do ar, podendo ser consideradas iguais em áreas homogêneas. No estudo de Mutiibwa et al. (2015), os autores encontraram relações mais fortes entre temperatura do ar e temperatura de superfície 
(MODIS) para as estações do verão e outono, e relações mais fracas para o inverno e primavera. A pesquisa revelou que para a maioria das observações a diferença entre as duas temperaturas ficou próxima a $10^{\circ} \mathrm{C}$ para o horário da imagem.

\section{CONCLUSÕES}

A caracterização da temperatura em Santa Maria permitiu verificar a variação térmica do espaço urbano e seu entorno rural a partir da metodologia de implantação de pontos fixos de coletas de dados e imagens termais. Com a integração de dados de campo e orbitais, constatou-se nas áreas urbanas o predomínio de temperaturas superiores ao ambiente rural, embora, em alguns pontos situados em área rural também tenham ocorrido valores elevados de temperatura, sendo justificado pela presença de solo exposto. As maiores diferenças entre a temperatura do urbano e rural ocorreram nas estações da primavera e verão, principalmente nos períodos da noite e madrugada.

A implantação dos pontos fixos em áreas com diferentes características ambientais permitiu reiterar a importância da presença da vegetação para amenizar a temperatura elevada nas cidades. Nos pontos urbanos com menor presença de vegetação ( $\mathrm{T} 1$ e $\mathrm{T} 6)$ foram registradas as temperaturas mais elevadas, sendo áreas caracterizadas pelo predomínio de materiais construídos. Em contrapartida, nos pontos urbanos com vegetação (T5) os valores de temperatura foram menores. Nos pontos rurais, destacou-se o T3 com as menores temperaturas em decorrência da sua localização em maior altitude e com densa arborização.

A partir da comparação entre a temperatura de campo (Tar) e temperatura das imagens termais (TS), constatou-se que nas áreas urbanas a temperatura de superfície foi superior a temperatura do ar, em contrapartida, nas áreas rurais as diferenças entre os dois dados foram mínimas. 0 desenvolvimento da presente pesquisa também permitiu a construção de abrigos de baixo custo adaptáveis a diferentes tipos de sensores de temperatura. Destaca-se também que, quando não for possível a aquisição destes equipamentos, as imagens termais são alternativas gratuitas e eficientes, pois com a análise das mesmas também é possível identificar áreas com temperaturas mais elevadas e que necessitam de mais atenção em relação ao conforto térmico da população.

\section{AGRADECIMENTOS}

Agradecemos ao Conselho Nacional de Desenvolvimento Científico e Tecnológico ( $\mathrm{CNPq}$ ) pela bolsa de estudos que permitiu o desenvolvimento da pesquisa.

\section{REFERÊNCIAS BIBLIOGRÁFICAS}

AlVARES, C. A.; STAPE, J. L.; Sentelhas, P. C.; GONÇALVES, J. L. de M.; SPAROVEK, G. Koppen's climate classification map for Brasil. Meteorologische Zeitschrift, v. 22, n 6, p. $711-728,2014$. 
ALVES, D. B. Cobertura vegetal e qualidade ambiental na paisagem urbana de Santa Maria (RS). Dissertação (Mestrado em Geografia). Programa de Pós Graduação em Geografia, Universidade Federal de Santa Maria. Santa Maria, 2012.

AMORIM, D. M.; COSTA, D. S.; CARVALHO, P. G. S.de; GARRIDO, M. S.; GONÇALVES, I. C. M. Comparação de dados obtidos a partir de sensores de temperatura e umidade relativa do ar protegidos em um abrigo meteorológico de PVC. Revista Energia na Agricultura, v. 30, n. 2, p. 119 - 124, 2015.

BECKER, H. E.; ZIMMERMANN, N. E.; McVICAR, T. R.; VERGOPOLAN, A. B.; WOOD, E. F. Data descripition: Present and future Koppen-Geiger climate classification maps at 1-Km resolution. Scientific Data, 5:180214, 2018.

BURIOL, G. A.; ESTEFANEL, V; RIGHI, E. Z.; BRESSAN, V. C. Conforto térmico para os seres humanos nas condições de ambiente natural em Santa Maria, RS, Brasil. Ciência Rural, v. 45, n. 2, p. 223-230, 2015.

COLLISCHONN, E. Adentrando a cidade de Pelotas/RS para tomar-Ihe a temperatura. Revista do Departamento de Geografia USP, v. Especial, p. 9-23, 2016.

GAGO, E. J.; ROLDAN, J.; PACHECO-TORRES, R.; ORDÓÑEZ, J. The city anda urban heat islands: a review of strategies to mitigate adverse effects. Renewable and Sustainable Energy Reviwes, v. 25, p. 749 - 758, 2013.

GARTLAND, L. Ilhas de Calor: como mitigar zonas de calor em áreas urbanas. São Paulo: Oficina de Textos, 2010. 148p.

GERACE, A. \& MONTANARO, M. Derivation and validation of the stray light correction algorithm for the thermal infrared sensor onboard Landsat 8 . Remote Sensing of Environmental, v. 191, p. 246 - 257, 2017.

GOBO, J. P. A.; FARIA, M. R.; GALVANI, E. GONÇALVES, F. L.T.; MONTEIRO, L. M. Empirical model of human thermal comfort in subtropical climates: a first approach to the Brazilian Subtropical Index (BSI). Atmosphere, n. 9, p. 1-16, 2018.

GUAN, K. K. Surface and ambient air temperatures associated with different ground material: a case study at the University of California, Berkeley. Surface and air temperatures of Ground Material, p. 1 - 14, 2011.

HELDWEIN, A. B.; BURIOL, G. A.; STRECK, N. A. O clima de Santa Maria. Ciência\&Ambiente, n. 38, p.43-59, 2009.

INSTITUTO BRASILEIRO DE GEOGRAFIA E ESTATÍSTICA. (IBGE). Santa Maria RS. Disponível em: < https://cidades.ibge.gov.br/brasil/rs/santamaria/panorama> Acesso: 20 janeiro 2018.

LOPES, F. B.; BARBOSA, C. C. F.; NOVO, E. M. L.; ANDRADE, E. M.; CHAVES, L. C. G. Modelagem da qualidade das águas a partir de sensoriamento remoto hiperespectral. Revista Brasileira de Engenharia Agrícola e Ambiental, v. 18, p. $13-19,2014$.

MARCHIORI, J. N. A vegetação em Santa Maria. Ciência \& Ambiente, n. 38, p.93-112, 2009. 
MONTANARO, M., GERACE, A., ROHRBACH, S. Toward an operational stray light correction for the Landsat 8 thermal infrared sensor. Appl. Opt. v. 54 (13), p. 3963-3978, 2015.

MUTIIBWA, D.; STRACHAN, S. ALBRIGHT, T. Land Surface Temperature and Surface Air Temperature in Complex Terrain. IEEE Journal of Selected Topics in Applied Earth Observations and Remote Sensing, p. 1939 - 1404, 2015.

NDOSSI, M. I. \& AVDAN, U. Application of Open Source Coding Technologies in the Production of Land Surface Temperature (LST) Maps from Landsat: a PyQGIS Plugin. Remote Sensing, v. 8, n. 5, 2016.

NORMAN, J. M. \& BECKER, F. Terminology in thermal infrared remote sensing of natural surfaces. Agriculture and Forest Meteorology, v. 77, n. 3-4, p. 153 166, 1995.

OKE, T. R. Boundary Layer Climates. London: Metheuen \& Co, 1978.

RADHI, H.; KIKRY, F.; SHARPLES, S. Impacts of urbanisation on the thermal behaviour of new built up environments: A scoping study of the urban heat island in Bahrain. Landscape and urban planning, v. 113, p. 47 -61, 2013.

ROSS, J. L. S. Geografia do Brasil. São Paulo: EDUSP, 2001.

ROSSATO, M. S. Os climas do Rio Grande do Sul: variabilidades, tendências e tipologia. 2011. 253f. Tese (Doutorado em Geografia). Universidade Federal do Rio Grande do Sul, 2011.

SANTAMOURIS, M. Cooling the cities - A review of reflective and green roof mitigation technologies to fight heat island and improve comfort in urban environments. Solar Energy, v 103, p. 682 - 703, 2014.

SARTORI, P. L. P. Geologia e Geomorfologia de Santa Maria. Ciência \& Ambiente. Santa Maria, n. 38, p.19-43, 2009.

SARTORI, M.G.B. O Vento Norte. Santa Maria: Gráfica e Editora Palloti, 2016. $256 \mathrm{p}$.

STEENEVELD, G. J.; KOOPMANS, B. G.; THEEUWES, N. E. Refreshing the role of open water surfaces on mitigating the maximum urban heat island effect. Landscape and Urban Planning, v. 121, p. 92 - 96, 2014.

STREUTKER, D. R. A remote sensing study of the urban heat island of Houston, Texas. International Journal of Remote Sensing, v.23, n.13, p.2.595-2.608, 2002.

TRINDADE, P. M. T.; SALDANHA, D. L.; PEREIRA FILHO, W. Utilização do infravermelho termal na análise espaço temporal da temperatura de superfície e ilhas de calor urbanas. Revista Brasileira de Cartografia, v.69, n. 4, p. 837-855, 2017.

YU, X.; GUO, X.; WU, Z. Land surface temperature retrieval from Landsat 8 TIRS - comparison between Radiative Transfer Equation - based method, Split Window Algorithm and Single Channel Method. Remote Sensing, 6, p. 9829 9852, 2014.

YUAN, F. \& BAUER, M. E. Comparison of impervious surface area and normalized difference Vegetation index as indicators of surface urban heat island effects in Landsat imagery. Remote Sensing of Environment, xx, p. $1-12,2006$. 
VALOR, E. \& CASELES, V. Mapping Land surface emissivity from NDVI: application to European, African, and South Americas areas. Remote Sensing of Environment, v. 7, p. 167- 184, 1996.

VAN de GRIEND, A. A. \& OWE, M. On the relationship betweem thermal emissivity and the normalized difference vegetation index for natural surfaces. International Journal Remote Sensing, v. 14, p. 1119 - 1131, 1993.

WMO. Guide to Meteorological Instruments and Methods of Observation. WMO n०8, 2008.

ZHANG, J.; WANG, Y.; LI, Y. A C ++ program for retrieving land surface temperature from the data of Landsat TM/ETM+ band6. Computers \& Geociences, v. 32, p. $1796-1805,2006$. 